\title{
COMPETÊNCIAS REQUERIDAS DO DIRETOR E DO COORDENADOR DE CURSO DE GRADUAÇÃO EM ENFERMAGEM DA UNIVERSIDADE ESTÁCIO DE SÁ/RJ
}

\author{
Miriam Garcia Leoni ${ }^{1}$, Lúcia de Fátima Silva de Andrade ${ }^{2}$, Elizabeth Carla Vasconcelos ${ }^{3}$
}

\begin{abstract}
RESUMO: Trata-se de um relato de experiência de implantação do Curso de Graduação em Enfermagem da Universidade Estácio de Sá/RJ. O objetivo foi conhecer as competências requeridas pelos Coordenadores e pelo Diretor do Curso de Graduação em Enfermagem para melhor gerenciar o processo de implantação. A Diretora com as Coordenadoras dos campi se reuniram para uma auto-avaliação mediante o uso de um questionário com perguntas abertas sobre quais competências deveriam ser desenvolvidas para melhor gerenciar o Curso. O questionário foi respondido pelos gerentes e a Diretora. Essa auto avaliação ocorreu no ano de 2002, com os $3^{\circ}$ e $4^{\circ}$ períodos em curso ministrados em cinco campi: Campus Rebouças, Campus Akxe, Campus Bangu, Campus Campos dos Goytacazes, Campus Nova Friburgo. Concluímos que para realizar uma gerência eficiente e eficaz é necessário que as seguintes competências devam ser desenvolvidas: competência técnica (conhecimento de Enfermagem), administrativa, pedagógica e emocional.

PALAVRAS-CHAVE: Programas de Graduação em Enfermagem; Gerência; Competência Profissional.

\section{REQUIRED COMPETENCIES ON THE PART OF THE DIRECTOR AND THE COORDINATOR OF THE NURSING GRADUATION COURSE AT UNIVERSITY ESTÁCIO DE SÁ/RIO DE JANEIRO-BRAZIL}

\begin{abstract}
It is an experience account about the implementation of the Nursing Graduation Course at University Estácio de Sá/Rio de Janeiro - Brazil. It objectified to learn about the competencies required by Coordinators and the Director of the Nursing Graduation Course for a better management of the implementation process. The Director along with the campi Coordinators met in order to perform a self-assessment by means of a questionnaire with open questions on the required competencies for a better course management. The questionnaire was answered by managers and Director. This selfassessment occurred in the year of 2002, with the third and fourth terms of the course in five campi: Rebouças, Akxe, Bangu, Campos dos Goytacazes and Nova Friburgo. We concluded that efficient and effective management is deemed necessary so that the following competencies must be developed: technical competency (Nursing knowledge) as well as administrative, pedagogical and emotional competencies.

KEYWORDS: Nursing Graduation Programs; Management; Professional Competency.

\section{CAPACIDADES QUE DEBEN TENER EL DIRECTOR Y EL COORDINADOR DE GRADUACIÓN EN ENFERMERÍA DE LA UNIVERSIDAD ESTÁCIO DE SÁ/RIO DE JANEIRO-BRASIL}

RESUMEN: Se trata de un relato de experiencia de la implantación del curso de graduación en enfermería de la Universidad Estácio de Sá - RJ. El objetivo fue saber las capacidades que deben tener los coordinadores y el director del curso de enfermería a fin de mejor manejar el proceso de implantación. La dirección y los coordinadores de campus se juntaron para hacer una autoevaluación. Fue aplicado un cuestionario con preguntas abiertas acerca de las capacidades que deberían ser desarrolladas para conducir el curso. El cuestionario fue contestado por todos los encargados, incluyendo el director. Esta autoevaluación ocurrió en el año de 2002, con los períodos $3^{\circ}$ y $4^{\circ}$ del curso, siendo hecha en cinco campus: Rebouças, Akxe, Bangu, Campos dos Goytacazes y Nova Friburgo. Se concluyó que, para llegar a una gerencia eficiente, es necesario que las siguientes capacidades sean desarrolladas: técnica (conocimiento del oficio de enfermera), administrativa, pedagógica y emocional.

PALABRAS CLAVE: Programas de Graduación en Enfermería; Administración; Competencia profesional.

${ }^{1}$ Enfermeira. Doutora em Enfermagem. Professora. Coordenadora do Curso de Graduação em Enfermagem da Universidade Estácio de Sá. ${ }^{2}$ Enfermeira. Doutora em Enfermagem. Professora. Escola de Enfermagem Anna Nery-Universidade Federal do Rio de Janeiro-UFRJ. ${ }^{3}$ Enfermeira. Doutora em Enfermagem. Professora. Escola de Enfermagem Aurora Afonso Costa-Universidade Federal Fluminense-UFF.

Autor correspondente:

Elizabeth Carla Vasconcelos

Rua Colatino Gusmão, 26 - 28035-023 - Campos dos Goytacazes-RJ

Recebido: 11/08/07

E-mail: bethcarla@terra.com.br

Aprovado: 13/05/08 


\section{INTRODUÇÃO}

Nos anos 1990, com a Lei de Diretrizes e Bases da Educação Nacional no 9.394/96 ${ }^{(1)}$, inicia-se uma reorientação no ensino superior, dando funções às universidades, com autonomia didática, administrativa e financeira, por desenvolver ensino, extensão e pesquisa. Em outubro de 1998, realizou-se em Paris, na França, a Conferência Mundial sobre Educação Superior pela Organização das Nações Unidas para a Educação-UNESCO, discutiu-se a educação superior, sua missão e desafios. Destacou a formação de cidadãos do mundo de amanhã, cidadãos autônomos, críticos, polivalentes, criativos, capazes de discernir os múltiplos desafios que o século XXI certamente trará. A função da Educação Superior é o preparo dos cidadãos do futuro, de um mundo em transição, este setor deve se tornar um espaço democrático de aprendizagem permanente, ao qual as pessoas tenham acesso em qualquer momento da vida ${ }^{(2)}$.

Sabe-se que a formação assume hoje um papel que transcende àquele ensino que pretende a mera atualização científica pedagógica e didática. Ela se transforma na possibilidade de criar espaços de participação, reflexão e formação, para que as pessoas adquiram conhecimento e sejam preparadas para poder conviver com a mudança e a incerteza, que não só se limita aos anos de estudos na Universidade, e sim faz parte de um processo contínuo ao longo da vida.

As últimas Diretrizes Curriculares Nacionais, aprovadas pelo MEC desencadearam um processo de implantação de novos currículos nos cursos de graduação na área da Saúde. Esse processo reforça a necessidade da articulação entre Educação Superior e Saúde, objetivando a formação geral e específica dos egresso-profissionais, com ênfase na promoção, prevenção, recuperação e reabilitação da saúde. Temse como perfil do egresso/profissional um enfermeiro com formação generalista, humanista, crítica e reflexiva, enfim, um profissional qualificado para o exercício da Enfermagem, com base no rigor científico e intelectual e pautado nos princípios éticos.

As Diretrizes Curriculares dos Cursos de Graduação em Enfermagem ${ }^{(3)}$, Resolução CNE/CES $n^{0} 03 / 01$, adquirem materialidade a partir de propostas que emergiram da mobilização dos enfermeiros, por meio da associação de classe, de entidades educacionais e de setores da sociedade civil interessados em defender as mudanças da formação na área da saúde. Elas expressam os conceitos originários dos movimentos por mudanças na educação em Enfermagem, explicitando a necessidade do compromisso com princípios da Reforma Sanitária Brasileira e do Sistema Único de Saúde-SUS. Essas diretrizes vêm ao encontro das políticas de Saúde e estão de acordo com o Ministério da Saúde, que propõe a reorientação dos cursos de graduação dessa área, oferecendo cooperação técnica, operacional e financeira, para que esses cursos possam desenvolver um trabalho articulado com a gestão, com os serviços do SUS e com a população em geral que é reconhecido como um programa de parceria desses ministérios EDUCARSUS a partir de 2004(4).

Este estudo surgiu da experiência das autoras, na implantação do Curso de Graduação em Enfermagem da Universidade Estácio de Sá/RJ que possui características multicampi, o que requer competências diferenciadas para administrá-la a partir dessa realidade uma questão que nos inquietava naquele período era: Quais competências gerenciais deverão ter o Diretor e o Coordenador do Curso de Graduação em Enfermagem com características multicampi? Assim, o objetivo desse estudo foi conhecer quais eram as competências requeridas dos Coordenadores e do Diretor do Curso de Graduação em Enfermagem em uma Universidade com características multicamp durante o seu período de implantação.

\section{DESCRIÇÃO DO LOCAL DE ESTUDO}

O cenário deste estudo foi o Curso de Graduação em Enfermagem da Universidade Estácio de Sá. Essa escolha se justifica por ser um curso com a característica de ter o corpo docente oriundo da prática assistencial e pertencer a uma instituição da rede privada.

A Universidade tem sede no Rio de Janeiro, com campi em outras cidades do Estado, tendo como missão produzir, sistematizar e socializar o saber científico, filosófico, artístico, cultural e tecnológico, com qualidade, ampliando e aprofundando a formação do discente para o exercício competente da profissão. Este Curso de Graduação em Enfermagem foi autorizado pela Resolução $n^{\circ}$. 32/CONSUNI/AR, de 07/03/97, e implantado no $2^{\circ}$ semestre de 2000 quando a Universidade considerou haver condições técnicas e operacionais adequadas para desenvolver o projeto pedagógico com a qualidade pretendida.

Nestes sete anos de história, o curso vem mantendo o seu compromisso de articular a formação e o exercício profissional às reais e atuais tendências 
emanadas pelos representantes da categoria, além das necessidades do mundo do trabalho, de forma a contribuir para a formação de um profissional promissor, eficiente e eficaz.

A missão do curso é formar enfermeiros qualificados para atuar em todos os níveis de complexidade da assistência ao ser humano em sua integralidade, no contexto do SUS e do sistema de saúde complementar, numa perspectiva críticoreflexiva-criativa, compromissado com a qualidade de vida da população, bem como, com sua qualificação permanente e com o desenvolvimento da profissão.

O Enfermeiro egresso deste Curso deverá ter adquirido formação generalista, humanista, criativa, crítica e reflexiva. Deverá também desenvolver competências e habilidades que possibilitem sua qualificação para o exercício da Enfermagem nas dimensões do cuidar, gerenciar, educar e investigar cientificamente, com base em princípios éticos, conhecimentos específicos e interdisciplinares. Deve ser capaz de intervir no processo saúde/doença através das ações de promoção, proteção e recuperação da saúde com ênfase no atendimento integral. Propõe a Educação Problematizadora, também chamada de Libertadora por Paulo Freire, e que integra as concepções pedagógicas que compõe a corrente crítica da educação, como a fundamentação pedagógica que caracterizará o enfermeiro formado por este Curso.

Este estudo ocorreu no ano de 2002, quando o curso se encontrava entre o terceiro e o quarto períodos, sendo ministrados em cinco campi: Campus Rebouças ( $4^{\circ}$ período), Campus Akxe ( $4^{\circ}$ período), Campus Bangu ( $3^{\circ}$ período), Campus Campos dos Goytacazes ( $3^{\circ}$ período), Campus Nova Friburgo ( $3^{\circ}$ período). O curso encontrava-se estruturado com uma direção geral e cinco coordenações locais.

A Diretora do Curso com as coordenadoras dos campi reuniram-se para fazer uma auto avaliação, para isso foi aplicado um questionário com perguntas abertas sobre quais competências deveriam ser desenvolvidas para melhor gerenciar o Curso. $\mathrm{O}$ questionário foi distribuído e respondido pelos cinco gerentes, e pela diretora, totalizando seis sujeitos. As respostas foram analisadas e discutidas pelo grupo.

\section{APRESENTANDO A TEIA DE RELAÇÕES DO CURSO ENTRE A DIRETORA E AS COORDENADORAS NAS VÁRIAS INSTÂNCIAS DA UNIVERSIDADE: UMA ARTICULAÇÃO PARA O SABER}

Este estudo foi abordado sob o ponto de vista da complexidade que Morin $^{(5: 188)}$ assim conceitua:

\footnotetext{
Complexus é o que está junto, é o tecido formado por diferentes fios que se transformam numa só coisa. Isto é, tudo isso se entrecruza, tudo se entrelaça para formar a unidade da complexidade; porém a unidade do complexus não destrói a variedade e a diversidade das complexidades que o teceram.
}

A Universidade é um sistema complexo. O que significa um sistema na visão complexa? Quanto ao conceito de sistema, Morin ${ }^{(5: 264-5)}$ afirma que deve ser tratado como um conceito de três faces: sistema (que exprime a unidade complexa e o caráter fenomenal do todo, assim como o complexo das relações entre o todo e as partes; interação (que exprime o conjunto das relações, ações e retroações que se efetuam e se tecem num sistema); organização (que exprime o caráter construtivo dessas interações - aquilo que forma, mantém, protege, regula, rege, regenera-se - e que dá a idéia de sistema a sua coluna vertebral).

Esses três termos são indissolúveis; remetem uns aos outros; a ausência de um mutila gravemente o conceito: o sistema sem conceito de organização é tão mutilado como a organização sem conceito de sistema. Trata-se de um macroconceito. É sobre este ponto de vista que abordaremos este estudo, o sistema complexo em que estão inseridas a Direção e as Coordenações do Curso de um Curso de Graduação em enfermagem com a presença deste em diversos Campi.

Nossa preocupação se coaduna com Perrenoud (2) de que o papel da escola não deve ser somente passar conteúdos, e sim, preparar para a vida; acrescida da preocupação com a formação geral do enfermeiro, tendo em vista torná-lo competente. Perrenoud ${ }^{(2)}$ enfoca competência como a faculdade de mobilizar um conjunto de recursos cognitivos (saberes, capacidades, informações, entre outros) para solucionar com pertinência e eficácia uma série de situações em que o graduando irá se deparar na sua vida profissional.

Um dos grandes desafios a ser enfrentado pelas Coordenadoras e pela Direção do Curso foi a intricada rede de relações existente entre as várias instâncias da Universidade. A teia (Fig. 1 e 2) ilustra a posição em que se encontra a Coordenação e a Direção. Nestas condições, nota-se a interdependência existente entra as diversas instâncias, quais sejam: no caso do Coordenador: a Direção do Curso, os alunos, os professores, o Coordenador Acadêmico do Campus, a Direção do Campus, os funcionários da Secretaria, da Central de Informação, dos Monitores 
e funcionários dos Laboratórios e as outras instâncias externas a cada campus. A Direção passa por processo semelhante, interage com a Vice-Reitoria de Graduação, Sub-Reitoria de Saúde, Vice-Reitoria de administração e Finanças, setores de apoio, alunos, professores, direções e coordenações acadêmicas dos campi onde existe o curso, além de sofrer pressões da comunidade acadêmica e unidades de saúde externas. Nos esquemas a seguir, visualiza-se a intrincada teia de influências referidas (Fig. 1 e 2).

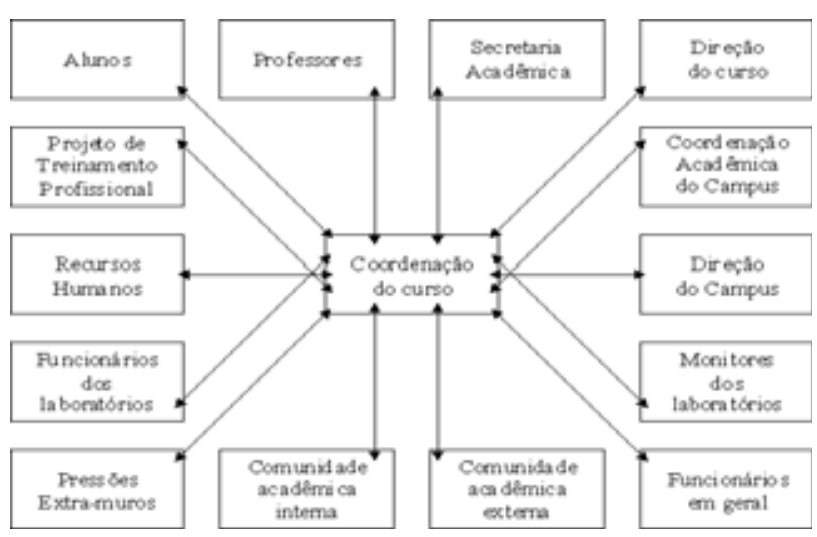

Figura 1 - Teia de relações das Coordenações de Curso e as demais instâncias da Universidade Estácio de Sá

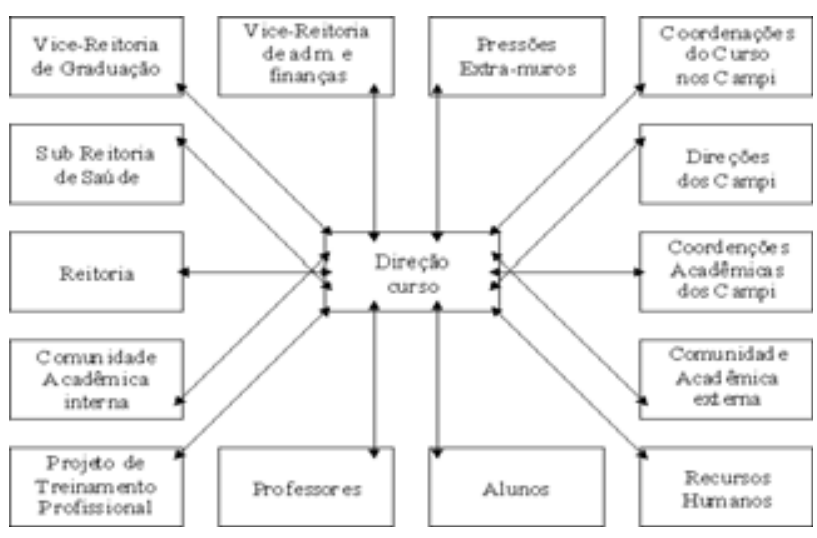

Figura 2 - Teia de relações da Direção do Curso e as demais instâncias da Universidade Estácio de Sá

Tais circunstâncias exigem tanto da Direção do Curso quanto das Coordenadoras ações de flexibilidade e respeito à diversidade, tendo em vista a multidimensionalidade existente na realidade de sua práxis. A respeito da multidimensionalidade, Morin ${ }^{(1)}$ afirma que a aspiração à complexidade tende para o conhecimento multidimensional, ela não quer dar todas as dimensões de um fenômeno estudado, mas respeitar suas diversas dimensões. Ao aspirar a multidimensionalidade, o pensamento complexo comporta em seu interior um princípio de incompletude e de incerteza. Isso nos levou sempre à ação com muita reflexão conjunta do grupo, já que sempre trabalhamos como um colegiado.

Para enfrentarmos a complexidade do real, pensamos que é preciso lançar mão de recursos próprios, cognitivos e afetivos para podermos ir e vir, nos diversos meandros da Instituição, que nos apresenta em todo o momento situações de complexidades variáveis, sendo necessário então desenvolvermos competências específicas que nos ajudem tomarmos decisões e agirmos da melhor forma possível.

\section{CONSIDERAÇÕES FINAIS}

A análise dos questionários demonstrou que as competências exigidas da Direção e das Coordenações do Curso se adéquam com o conceito de competência de Perrenoud (6:21) que a conceitua como: "a capacidade de um sujeito de mobilizar o todo ou parte de seus recursos cognitivos e afetivos para enfrentar uma família de situações complexas”. Para o citado autor, isso exige a conceituação precisa desses recursos, das relações que devem ser estabelecidas entre eles e da natureza do "saber mobilizar". Pensar em termos de competência significa pensar a sinergia, a orquestração de recursos cognitivos e afetivos diversos para enfrentar um conjunto de situações que apresentam analogias de estruturas. As respostas da direção/coordenações apontaram para as seguintes competências: técnica (conhecimento de Enfermagem), administrativa, educacional (pedagógicas) e emocional. A respeito da importância do conhecimento técnico, ou seja, conhecer a Enfermagem, a Direção do Curso optou por chamar para as Coordenações do Curso nos diversos campi, enfermeiras que atuavam na prática assistencial.

Os professores também quando selecionados seguiu o mesmo critério. O que nos facilitou bastante nos assuntos referentes aos aspectos do conhecimento prático da Enfermagem, mas por outro lado nos criou dificuldades por não termos experiência docente, por causa dessa questão, a Direção optou por preparar as Enfermeiras também para a prática docente através de Oficinas realizadas em parceria com o Curso de Pedagogia da Universidade Estácio de Sá no sentido de capacitar para a Docência as enfermeiras que tinham domínio da prática, mas apresentavam dificuldades específicas referentes às questões pedagógicas. No aspecto administrativo, podemos enfatizar que na formação das Enfermeiras esse aspecto é bem aprofundado, o que foi de grande ajuda, porém, houve 
necessidade de buscar conhecimentos administrativos voltados para administração escolar em nível superior.

Em relação à questão da emoção, aspecto muitas vezes deixado para segundo plano. Temos observado na nossa práxis a relevância deste para uma atuação eficaz. Sobre este aspecto Goleman ${ }^{(7: x i)}$ afirma: “A missão básica da liderança é de cunho emocional.” Com esta afirmação incluímos aqui o cunho de liderança emocional que estes cargos carreiam no bojo de sua execução. Embora não raras vezes essa dimensão básica da liderança permaneça na invisibilidade, ou seja, ignorada. $\mathrm{O}$ autor nos mostra sua importância para a qualidade da liderança e a nossa vivência prática confirma essa afirmação.

Na nossa autoavaliação as respostas do grupo reforçaram o desenvolvimento de competências que já imaginávamos, tais como: técnica (conhecimento de Enfermagem), administrativa, educacional (pedagógicas), porém, a emoção foi um achado que nos surpreendeu, a descoberta do papel das emoções no ambiente de trabalho nos remete a aspectos tangíveis, como o moral elevado, motivação e comprometimento.

A peculiaridade e as características singulares dos cargos em estudo nos levam a dar mais importância à arte das relações humanas como um fator altamente influente, que deve ser considerado como relevante quando falarmos nos cargos referidos, além de ser necessário que o gestor tenha conhecimentos sólidos da Profissão de Enfermagem, conhecimento dos princípios gerais de Administração e base também no conhecimento da Pedagogia.

Essas competências deveriam atender às diversas demandas do gerenciamento do Curso, no que diz respeito: ao embasamento técnico que possibilitasse a montagem de um Curso de Graduação em Enfermagem que atendesse às expectativas geradas na comunidade de Enfermagem com seu surgimento; pautado na experiência profissional das Enfermeiras que se encontravam à frente do mesmo, atendendo também às novas exigências do mundo do trabalho; ao desenvolvimento administrativo que contemplasse todos os níveis hierárquicos da Universidade em seus campi; às questões pedagógicas inerentes a uma Instituição de Ensino Superior, especificamente, de um Curso de Graduação em Enfermagem, como por exemplo, inteirar-se das novas diretrizes curriculares, e da proposta interdisciplinar da mesma, pois:

Os cursos de Educação Superior em Saúde no Brasil têm sofrido, através das Diretrizes Curriculares estabelecidas por Resoluções do Ministério da Educação.
A interdisciplinaridade tem se constituído em um elemento basilar das mudanças propostas, confluindo para ações que contribuem com a formação de profissionais dotados de postura crítica que atuarão em cenários complexos. ${ }^{(8: 366)}$

E também atender as necessidades de suporte emocional para transitar com eficácia e eficiência por todos os ambientes da Universidade, utilizando os relacionamentos intrapessoal, interpessoal e interprofissional de maneira a alcançar os objetivos propostos, ou seja, a implantação de um Curso de Graduação em Enfermagem com qualidade. O estudo é relevante para a sociedade, pois mostra a experiência vivenciada pelas autoras na implantação de um Curso de Graduação em Enfermagem que pode servir de parâmetro para outras Enfermeiras envolvidas em processo semelhante poderem desenvolver competências que possam colaborar na formação de enfermeiros competentes, prestando assim uma assistência de qualidade à população.

\section{REFERÊNCIAS}

1. Brasil. Presidência da República. Casa Civil. Lei nº 9.394, de 20 de dezembro de 1996. Estabelece as diretrizes e bases da educação nacional. [Acesso em 2008 Mai 11]. Disponível em www.planalto.gov.br

2. Mayor F. Discurso de Abertura In: Lázaro, A, organizador. Visão e ação: a universidade no século XXI. Rio de Janeiro: Eduerj; 1999.

3. Brasil. Conselho Nacional de Educação. Câmara de Educação Superior. Resolução CNE/CES nº 3, de 7 de nov de 2001. Institui as Diretrizes Curriculares Nacionais do Curso de Graduação em Enfermagem. Diário Oficial da União, Brasília, 09 de novembro de 2001. [Acesso em 2008 Mai 11]. Disponível em www.portal.mec.gov.br

4. Brasil. Associação Brasileira de Enfermagem. $8^{\circ}$ Seminário Nacional de Diretrizes para a Educação em Enfermagem (SENADEn). Carta de Vitória. www.abennacional.org.br/download

5. Morin E. Ciência com consciência. $5^{\mathrm{a}}$ ed. Rio de Janeiro: Bertrand Brasil; 2001.

6. Perrenoud, P. Ensinar: agir na urgência, decidir na incerteza. $2^{\mathrm{a}}$ ed. Porto Alegre: Artmed; 2001.

7. Goleman D., Boyattzis R., Mckee A. O poder da inteligência emocional. Rio de Janeiro: Campus; 2002.

8. Bagnato MHS; Renovato RD; Bassinello GAH. De interdisciplinaridade e multireferencialidade na educação superior em saúde. Cogitare Enferm. 2007 Jul/ Set;12(3):365-70 